\title{
As Externalidades da Alfabetização podem gerar uma porta de saída de curto prazo da pobreza para os beneficiários do Bolsa Família?
}

Felipe Garcia Ribeiro ${ }^{1}$

Luis Antonio Winck Cechin ${ }^{2}$

Resumo: Este trabalho tem por objetivo investigar a possível existência de um benefício positivo da educação das crianças em idade escolar para os adultos analfabetos, inseridos no Programa Bolsa Família, em decorrência das condicionalidades educacionais do Programa. Buscam-se sinais de externalidade da alfabetização no sentido dos filhos para os pais/adultos analfabetos, no quesito rendimento do trabalho. Utiliza-se o modelo de seleção de Heckman para corrigir o problema de autosseleção dos indivíduos em participar do mercado de trabalho. Os resultados apontam que os pais/adultos analfabetos, beneficiários do Programa Bolsa Família (PBF), e que residem com ao menos um filho alfabetizado recebem, em média, 10,96\% a mais do que os pais/adultos analfabetos, beneficiários do PBF, que não residem com filhos alfabetizados.

Palavras-chave: Programa Bolsa Família; Analfabetos não-Isolados; Analfabetos Isolados; Externalidades; Modelo de Seleção de Heckman.

JEL: D62, I38, O15.

\footnotetext{
1 Doutorando em Economia pela Fundação Getúlio Vargas (FGV/SP). Professor da Universidade Federal de Pelotas (UFPel). E-mail: felipe.garcia.rs@gmail.com

2 Graduado em Economia pela Universidade Federal de Pelotas (UFPel). E-mail: megawinck@hotmail.com
} 


\title{
Externalities Literacy can generate an output port short-term poverty for the Bolsa Família beneficiaries?
}

\begin{abstract}
This paper aims to investigate a possible positive benefit of the children's literacy in school age to illiterate parents who take part in the Bolsa Família Program due to the allowance educational conditionalities. Signs are sought to the externality of literacy from the children to their illiterate parents' earnings. Heckman's selection model has been used to fix the auto selection problem of the individuals in taking part of the labor market. The results point that illiterate parents/adults who receive the Bolsa Família Program and who lives in a househould with at least one literate child, earns on average, 10,96\% more than those illiterate parents recipient of the BFP who do not live with literate children.
\end{abstract}

Key-words: Bolsa Família Program; Proximate Literate; Isolated illiterate; Externalities; Heckman's Selection Model.

JEL: D62, I38, O15.

\section{Introdução}

A pobreza é tida como um limitador da obtenção de capacidades, ou seja, é uma importante causa de privações à alimentação, saúde e educação. Esses três itens, em conjunto, são os principais formadores do capital humano, o qual facilita o acesso ao mercado de trabalho, o aumento da produtividade, a inovação, e o desenvolvimento. Nesse contexto, o governo, ao identificar a pobreza como risco social, intervém na economia com políticas públicas que visam amenizar os efeitos da falta de renda e de oportunidades.

Amartya Sen (2000) considera a liberdade do indivíduo como elemento constitutivo básico para o desenvolvimento. Atenta que a expansão das "capacidades" tende a andar junto com o aumento da produtividade e do poder de auferir renda, e, portanto, são essenciais para a avaliação do crescimento social. Sen (2000: 125-126) ressalta que a redução da pobreza de renda não pode, em si, ser a motivação suprema de políticas de combate à pobreza, uma vez que, na sua concepção, temos, ainda, a pobreza de capacidades.

Com o intuito de reduzir a pobreza e de auxiliar na promoção do desenvolvimento das capacidades, foram implantados no Brasil, a partir da década de 90, diversos programas de transferência direta de renda para a população pobre. No âmbito Federal, os Programas de Transferência de Renda Condicionada (PTRC) seguiram a seguinte cronologia: em 1996, foi criado o Programa de Erradicação do Trabalho Infantil (PETI); em 2001, o Bolsa Escola e o Bolsa Alimentação; e, em 2003, foram criados o Cartão Alimentação e o Programa Bolsa Família. 
O Programa Bolsa Família (PBF) é responsável pela transferência direta de renda, que beneficia famílias em situação de pobreza e extrema pobreza. Através da sua característica de transferência condicionada de renda, o PBF visa no curto prazo amenizar as situações de extrema pobreza e pobreza. No longo prazo, aspira proporcionar uma maior qualificação para as famílias beneficiadas pelo Programa, induzindo, através das suas condicionalidades, o aprimoramento do capital humano e a esperada saída dessa situação de miserabilidade que a educação pode propiciar.

Nesse sentido, sem entrar no mérito da eficiência do gasto público na prestação dos serviços de educação e saúde, o PBF, ao instituir condicionalidades para a percepção do benefício, busca reduzir não apenas a pobreza de renda, mas também a pobreza de capacidades, seguindo, a lógica de Amartya Sen.

A transferência de renda direta do Governo aos domicílios tem um impacto direto sobre a renda disponível, afetando possivelmente de forma positiva o bem-estar das famílias no curto prazo. Já a acumulação de capital humano, estimulada pelas condicionalidades, espera-se que tenha um impacto positivo de longo prazo sobre a redução da pobreza, uma vez que o retorno do investimento em educação leva tempo para ser capturado. Entretanto, existe a possibilidade de que a educação possa gerar benefícios sociais positivos mesmo no curto prazo, tanto em aspectos monetários quanto não monetários para as famílias. Ventila-se a possibilidade de que no curto prazo possa haver externalidades positivas da alfabetização dos filhos que frequentam a escola sobre os demais integrantes dos domicílios beneficiários do PBF que não sejam alfabetizados.

A hipótese de que existem externalidades da alfabetização foi apontada inicialmente por Basu e Foster (1998). Segundo eles, indivíduos analfabetos podem ter acesso às atividades que requerem o uso de leitura e de escrita quando têm contato com pessoas alfabetizadas. Dessa forma, um analfabeto que tenha acesso fácil a uma pessoa alfabetizada se encontra em uma situação melhor do que um analfabeto que não disponha de tal acesso. Por exemplo, filhos alfabetizados podem ajudar pais analfabetos a utilizarem novas técnicas de produção em atividades laborais, ou auxiliar na busca por novas oportunidades de emprego. Dessa forma, a alfabetização de pelo menos um membro da família pode gerar uma externalidade positiva, proporcionando um bem público para os membros analfabetos.

Basu e Foster sugeriram a divisão dos analfabetos em duas categorias: Analfabetos não-Isolados e Analfabetos Isolados (deste ponto em diante ANI e AI, respectivamente). A primeira categoria se refere aos analfabetos que convivem com pessoas alfabetizadas, enquanto a segunda se refere aos analfabetos que são desprovidos de tal convívio. 
Isso posto, o presente trabalho visa testar, exclusivamente dentro dos domicílios beneficiários do PBF, evidências de externalidades da alfabetização no aspecto relacionado às variações dos rendimentos do trabalho. Para tanto, buscar-se-ão evidências de externalidade no sentido dos filhos (em atividade escolar) para os adultos analfabetos (pertencentes à População em Idade Ativa) que compõem o domicílio.

O estudo empírico das externalidades da alfabetização, dentre o grupo dos beneficiários do PBF, é relevante para a análise de uma possível "porta de saída" de curto prazo da pobreza, estimulada pelas condicionalidades educacionais do programa. Com as estimativas em mãos do impacto da alfabetização dos filhos sobre o rendimento dos adultos analfabetos pertencentes ao programa, formuladores de políticas poderão estimar se o que está sendo gasto é insuficiente, suficiente ou mais do que suficiente para a expansão das capacidades humanas em determinada região e a consequente mobilidade social em um prazo mais próximo do que o imaginado em decorrência de ganhos exclusivamente privados da educação. Em outras palavras, se comprovada à existência de externalidade da alfabetização para o quesito rendimento do trabalho dos adultos analfabetos, ficará evidenciado que a educação, além de promover o aumento das capacidades humanas dos estudantes, amplia o nível de riqueza do conjunto familiar.

A análise deste trabalho será realizada com base nos microdados da Pesquisa Nacional por Amostra de Domicílios (PNAD) do ano de 2006, por se tratar da última pesquisa domiciliar que aborda o PBF. É importante deixar claro desde já que condicional às variáveis que estão sendo observadas, a participação no mercado de trabalho não é uma atividade atribuível ao acaso. Dessa forma, os resultados obtidos via estimações por Mínimos Quadrados Ordinários (MQO) provavelmente se apresentam viesados, devido ao fato dos indivíduos participantes e não participantes do mercado de trabalho serem possivelmente diferentes em características observáveis e não observáveis. Para corrigir tal problema, será utilizado o modelo de seleção de Heckman que soluciona o viés de seleção e gera um contrafactual mais adequado para a investigação do impacto de interesse.

Este trabalho está dividido em mais seis seções além desta introdução. Na seção seguinte, será realizada a análise do PBF e do perfil de alfabetização da população brasileira sob os conceitos de analfabetismo isolado e nãoisolado. $\mathrm{Na} 3^{\mathrm{a}}$ seção, será realizada uma análise teórica das externalidades da alfabetização. $\mathrm{Na} 4^{\mathrm{a}}$ seção, será apresentada a revisão da literatura sobre estudos acerca do impacto do PBF na desigualdade social e no mercado de trabalho, bem como dos estudos realizados sobre a externalidade da alfabetização em países em desenvolvimento. A $5^{\mathrm{a}}$ seção discutirá sobre a estratégia empírica utilizada para atingir os objetivos propostos. $\mathrm{Na} 6^{\mathrm{a}}$ seção, será apresentada a avaliação empírica e os resultados encontrados. Após serão efetuadas as considerações finais. 


\section{O Programa Bolsa Família e o perfil de alfabetização}

A Lei n. ${ }^{0}$ 10.836/o4 instituiu um dos maiores programas de transferência direta de renda do mundo, o Programa Bolsa Família - PBF, que beneficia famílias em situação de pobreza e extrema pobreza. O PBF unificou os procedimentos de gestão e execução das ações de transferência de renda do Governo Federal, especialmente as do Bolsa Escola, do Programa Nacional de Acesso à Alimentação - PNAA (Cartão Alimentação), do Bolsa Alimentação, do Programa Auxílio-Gás, e do Cadastramento Único do Governo Federal.

O Programa de caráter condicionado distribui benefícios cujos valores, em 2006, variavam de $\mathrm{R} \$ 15,00$ a $\mathrm{R} \$ 95,00$ de acordo com a renda mensal per capita da família e com o número de crianças e adolescentes de até 15 anos. Inicialmente, o Programa Bolsa Família focava na faixa etária de 0 a 15 anos, porém, em 2008, o Programa foi alterado pela Lei n. ${ }^{0} 11.692 / 08$, passando a atender também a população de 16 e 17 anos. O PBF tem quatro tipos de benefícios, que variam em valores e também de acordo com a característica da família: o básico, o variável, o variável vinculado ao adolescente e o variável de caráter extraordinário.

O Benefício Básico não leva em consideração os filhos da família assistida, pois a condição necessária para a sua percepção é o enquadramento na situação de extrema pobreza (renda mensal de até $\mathrm{R} \$ 60,00$ por pessoa no ano de 2006). O valor mensal desse benefício era, em 2006, de R \$ 50,00.

O Benefício Variável é pago às famílias em situação de pobreza (renda mensal de $\mathrm{R} \$ 60,01$ até $\mathrm{R} \$ 120,00$ por pessoa no ano de 2006) que tenham crianças e adolescentes de até 15 anos, porém cada família podia receber no máximo três ${ }^{1}$ benefícios variáveis. O valor mensal desse benefício, em 2006, era de $\mathrm{R} \$ 15,00$, podendo totalizar $\mathrm{R} \$ 45,00$.

O Benefício Variável Vinculado ao Adolescente (BVJ) corresponde ao valor de $\mathrm{R} \$ 38,00$, que é pago a todas as famílias pertencentes ao Programa, que tenham adolescentes de 16 e 17 anos frequentando a escola. Porém cada família pode receber no máximo dois BVJ, que totalizam $\mathrm{R} \$ 76,00$.

O Benefício Variável de Caráter Extraordinário (BVCE) corresponde ao valor pago às famílias nos casos em que houve perdas financeiras na migração dos Programas Auxílio-Gás, Bolsa Escola, Bolsa Alimentação e Cartão Alimentação para o Bolsa Família.

1 Atualmente, por força da Medida Provisória n. ${ }^{\circ}$ 535, de 2 de junho 2011, o Benefício Variável é pago até o limite de cinco benefícios por família. O valor mensal deste benefício corresponde à quantia de $\mathrm{R} \$ 32,00$, podendo totalizar R $\$ 160,00$. 
Uma vez inserida a família no Programa, sua permanência fica vinculada às condicionalidades de frequência escolar mensal de 85\% para crianças (de 6 a 15 anos) e de $75 \%$ para adolescentes (de 16 e 17 anos), em estabelecimento de ensino regular. No âmbito da saúde, as condicionalidades são o acompanhamento do desenvolvimento infantil (inclusive cartão de vacinação) e acompanhamento das mulheres com idades entre 14 e 44 anos, bem como no caso de gestantes e lactantes a realização do pré-natal e o acompanhamento da sua saúde e do bebê. Além disso, as crianças e adolescentes com idade até 15 anos deverão participar de programas de convivência social, com frequência mínima mensal de $85 \%$.

De acordo com a folha de pagamento da CEF, a evolução da distribuição dos benefícios do Programa Bolsa Família entre as regiões do país se deu da seguinte maneira:

TABELA 1. NÚMERO DE FAMÍLIAS ATENDIDAS PELO PBF

\begin{tabular}{lrrrr}
\hline \multicolumn{1}{c}{ Região } & \multicolumn{1}{c}{ Dez./2004 } & \multicolumn{1}{c}{ Dez./2005 } & \multicolumn{1}{c}{ Jun./2006 } & \multicolumn{1}{c}{ Set./2011 } \\
\hline Norte & 537.145 & 713.345 & 1.012 .559 & 1.410 .491 \\
Nordeste & 3.397 .259 & 4.355 .774 & 5.568 .757 & 6.574 .660 \\
Centro-Oeste & 295.797 & 454.922 & 611.846 & 684.122 \\
Sudeste & 1.760 .129 & 2.394 .654 & 2.950 .434 & 3.098 .599 \\
Sul & 712.058 & 1.023 .420 & 1.074 .203 & 980.708 \\
Brasil & 6.702 .388 & 8.942 .115 & 11.217 .799 & 12.748 .580 \\
\hline
\end{tabular}

Fonte: TCU/CEF.

TABELA 1 (cont.). NÚMERO DE FAMÍLIAS ATENDIDAS PELO PBF

\begin{tabular}{lrrr}
\hline \multicolumn{1}{r}{ Região } & $\begin{array}{c}\text { PBF \% } \\
2006\end{array}$ & $\begin{array}{c}\text { PBF \% } \\
2011\end{array}$ & $\begin{array}{c}\text { Expansão \% } \\
\text { 2011/2006 }\end{array}$ \\
\hline Norte & 9,03 & 11,06 & 39,30 \\
Nordeste & 49,64 & 51,57 & 18,06 \\
Centro-Oeste & 5,45 & 5,37 & 11,81 \\
Sudeste & 26,30 & 24,31 & 5,02 \\
Sul & 9,58 & 7,69 & $-8,70$ \\
Brasil & 100,00 & 100,00 & 13,65 \\
\hline
\end{tabular}

Fonte: TCU/CEF. 
Através dos dados da tabela 1, verifica-se que no período de 2006 a 2011 houve expansão da quantidade de famílias atendidas pelo PBF em quase todas as regiões do país, excetuando-se a região Sul que teve queda de 8,70\%. Essa redução pode ser compreendida através da Nota Conjunta ${ }^{2}$ SENARC/MDS, DISOC/IPEA ao TCU, a qual informa que houve, no período de 2001 a 2004, uma redução significativa das estimativas de famílias pobres nas regiões Sul e Centro-Oeste. No entanto, nesse mesmo período houve aumento do número de famílias pobres na região Nordeste.

De acordo com os dados da PNAD de 2006, 49,18\% dos beneficiários do PBF pertenciam a domicílios com renda per capita familiar superior a $\mathrm{R} \$ 120,00$. A hipótese de incompatibilidade de renda com recebimento do benefício do PBF pode ser explicada por: i) A família informou equivocadamente o valor da renda de seus integrantes ao recenseador; ii) Indícios de fraude, apontados no relatório do TCU3 .

Do total de beneficiários do PBF restam, ainda, 50,82\% (44.606 domicílios). Esse percentual representa uma amostra suficiente para o propósito deste trabalho. Além do que, ao analisar as pessoas que, em 2006, viviam com renda per capita familiar de até $\mathrm{R}$ \$120,00, analisa-se o público alvo do Programa, ou seja, as pessoas que realmente viviam nas situações de extrema pobreza e pobreza. É importante ressaltar que as análises seguintes são oriundas exclusivamente dessa população, a qual representa fielmente as situações de vulnerabilidade social.

TABELA 2. PERFIL DA ALFABETIZAÇÃO E REPRESENTATIVIDADE DOS ANALFABETOS NO MERCADO DE TRABALHO

\begin{tabular}{l|c|c|c|c|c|c}
\hline \multicolumn{6}{c}{ Analfabetos com renda per capita familiar de até R\$ 120,00 } \\
\hline Região & Analfabetos & ANI & AI & $\begin{array}{c}\text { Analfabetos } \\
\text { na PEA }\end{array}$ & $\begin{array}{c}\text { Ocupados } \\
\text { analfabetos }\end{array}$ & $\begin{array}{c}\text { Analfabetos } \\
\text { no emprego } \\
\text { formal }\end{array}$ \\
\hline Norte & 15,22 & 13,40 & 1,83 & 17,01 & 18,88 & 11,37 \\
Nordeste & 22,21 & 19,10 & 3,11 & 25,23 & 28,00 & 19,20 \\
Centro-Oeste & 10,34 & 9,14 & 1,20 & 11,84 & 12,79 & 10,24 \\
Sudeste & 9,39 & 8,28 & 1,11 & 9,71 & 11,56 & 8,70 \\
Sul & 8,61 & 7,73 & 0,88 & 8,60 & 9,30 & 7,24 \\
Brasil & 17,30 & 15,00 & 2,30 & 19,62 & 22,20 & 13,82 \\
\hline
\end{tabular}

Fonte: PNAD 2006.

2 Informação transcrita ao relatório de acompanhamento do PBF do Tribunal de Contas da União (TCU), Vide:http://portal2.tcu.gov.br/portal/page/portal/TCU/comunidades/programas_governo/areas_atuacao/ assistencia_social/Relat\%C3\%B3rio\%20de\%20Acompanhamento\%20do\%20PBF_janeiro_o.pdf.

3 O TCU informou no relatório de 2008 que, entre 2004 e 2006, houve indícios de fraude. Vide: http:// portal2.tcu.gov.br/portal/page/portal/TCU/comunidades/assistencia_social/CG_20o8_Relatorio_ Completo\%5B1\%5D.pdf. 
A tabela 2 apresenta o perfil da alfabetização e a representatividade dos analfabetos pobres e extremamente pobres no mercado de trabalho. As informações dessa tabela dizem respeito aos beneficiários e nãobeneficiários do PBF. Os percentuais apresentados nas linhas da tabela são referentes à população daquela linha (região). Por exemplo, 15,22\% das pessoas da região Norte são analfabetas, enquanto no nordeste esse mesmo número é de $19,10 \%$.

A análise preliminar da população de interesse é importante para que se possam observar algumas características do público-alvo. Por exemplo, os microdados da PNAD 2006 relatam que, em nível nacional, 19,62\% da População Economicamente Ativa (PEA) é composta por analfabetos, e estes representam 22,20\% do total de ocupados, já em relação ao emprego formal, os analfabetos representam $13,82 \%$ do total.

Ante o acima exposto, verifica-se que as regiões Norte e Nordeste são as mais pobres e as que contêm os maiores índices de ANI e AI. Desse modo, identificadas as peculiaridades da população pobre em cada região no que se refere ao mercado de trabalho e ao analfabetismo, é possível visualizar o perfil populacional sobre o qual será desenvolvido o presente estudo.

Por fim, de acordo com os microdados da PNAD 2006, em todas as regiões do país, mais de $90 \%$ das crianças de 7 a 17 anos frequentam a escola. Provavelmente, essas crianças terão uma ampliação do seu capital humano, o que poderá colaborar com a redução da pobreza no longo prazo. Porém, este estudo busca, mesmo no curto prazo, um possível benefício positivo da educação para as famílias inseridas no PBF, em decorrência das condicionalidades educacionais do Programa. Assim, se os rendimentos do trabalho dos pais/adultos (ANI) beneficiários do Programa são afetados positivamente pela educação dos filhos, ficará evidenciado que a alfabetização gera externalidades capazes de ampliar o nível de bem-estar familiar.

\section{Externalidades da alfabetização}

Quando um agente qualquer produz ou consome um determinado bem e outras pessoas são afetadas pela produção ou consumo desse bem, sem que elas paguem ou sejam ressarcidas pelo impacto recebido, esse agente gera uma externalidade, a qual pode ser positiva (gerando benefícios) ou negativa (gerando prejuízos).

Dessa maneira, externalidades positivas ocorrem quando um benefício externo é gerado pela produção de um bem, ou seja, ocorrem quando os benefícios sociais são superiores ao benefício privado. Nesse contexto, os benefícios privados da educação podem ser percebidos, por exemplo, através dos salários obtidos em função do nível de escolaridade. Já os benefícios sociais 
da educação podem ser percebidos através de uma sociedade educada capaz de obter melhores níveis de saúde e menores índices de criminalidade, bem como através de uma força de trabalho educada, a qual pode ser capaz de criar e adotar novas tecnologias.

Basu e Foster (1998) apontam a hipótese de externalidades da alfabetização em âmbito intra-domiciliar. Segundo os autores, a alfabetização de pelo menos um membro da família gera uma externalidade positiva, proporcionando, desta forma, um bem público para os membros analfabetos.

De acordo com a teoria econômica, um bem para ser considerado público exige que o seu consumo seja não-excludente e não-rival. Desse modo, no caso da alfabetização ser um bem público, a impossibilidade de exclusão em âmbito intra-domiciliar sugere que os adultos analfabetos não poderiam ser privados de usufruir da alfabetização das demais pessoas que residem no mesmo domicílio. Já a não rivalidade no consumo sugere que, uma vez estando disponível o bem (no caso, a alfabetização de algum integrante do domicílio), o custo marginal de proporcioná-lo para um indivíduo adicional seria nulo.

Na concepção de Basu et al. (2001), os benefícios da alfabetização, em geral, são não-rivais, mas excludentes. Segundo os autores, a não rivalidade decorre da ausência de custos para que um alfabetizado possa ler um folheto ou dar uma informação a um analfabeto. Porém, a externalidade da alfabetização é excludente porque a pessoa alfabetizada, se quiser, pode ocultar alguma informação do analfabeto. Para os autores, mesmo que alguns benefícios possam ser adquiridos por osmose, ainda assim, a pessoa alfabetizada pode bloquear vários benefícios (informações), se assim desejar.

As decisões de consumo da família são afetadas pelo "poder de barganha” de cada membro, ou seja, pela capacidade que cada pessoa tem de interferir nos gastos da família. Nesse contexto, é de se esperar que indivíduos educados possuam uma melhor percepção de desigualdade, bem como uma melhor posição de negociação dentro da família.

Basu et al., observam que se as preferências entre alfabetizados e analfabetos (do mesmo domicílio) são diferentes, o compartilhamento da alfabetização pode gerar uma mudança no "poder de barganha" em desfavor do membro alfabetizado, o qual irá, naturalmente, nessa situação, ser inclinado a não compartilhar as vantagens da alfabetização.

Diante dessa proposição, Basu et al. desenvolveram um modelo econômico para captar a externalidade da alfabetização no âmbito intra-domiciliar. Nesse modelo, os membros alfabetizados têm a liberdade de restringir vantagens da alfabetização aos membros analfabetos. Dessa forma, a escolha de compartilhar essas vantagens, na mesma unidade familiar, depende dos ganhos de utilidade pessoal dos alfabetizados, uma vez que esse compartilhamento pode alterar o nível e a composição do consumo de bens da família. 
Para simplificar, os autores partem de uma família com apenas duas pessoas, sendo uma alfabetizada e a outra analfabeta. Essa família consome apenas dois bens e ambos são identificados por bens privados. As funções de utilidade para alfabetizados e analfabetos são, respectivamente, $U_{L}$ e $U_{o}$. Sendo $x$ o vetor de bens consumidos, as utilidades passam a ser $U_{L}(x)$ e $U_{o}(x)$. De acordo com Basu et al., as funções de utilidade são estritamente crescentes e quase-côncavas. Desse modo, a família maximiza a média ponderada de $U_{L}$ e $U_{o}$, com peso $\lambda$ das funções de renda da pessoa analfabeta $\left(y_{0}\right)$ e da pessoa alfabetizada $\left(y_{L}\right)$. No modelo dos autores, $y_{L}$ torna-se constante, de modo que $\lambda$ é uma função de $\left(y_{0}\right)$. Então, pressupondo que $\lambda\left(y_{0}\right) \in[0,1]$ e $\lambda^{\prime}\left(y_{0}\right) \geq 0$, o problema da unidade familiar é escolher $x$ de forma a maximizar:

$$
\begin{aligned}
& \lambda\left(y_{o}\right) U_{o}(x)+\left[1-\lambda\left(y_{o}\right)\right] U_{L}(x) \\
& \text { p. } x \leq y_{L}+y_{o}
\end{aligned}
$$

em que $p=\left[p_{1}, p_{2}\right]$ representa o vetor de preços para os dois bens.

A solução do problema ${ }^{4}$ denotada pelos autores foi:

$$
x=x\left(y_{o}\right)
$$

O valor de $y_{o}$ dependerá, em parte, da escolha da pessoa alfabetizada, pois se essa pessoa não excluir o analfabeto da externalidade da alfabetização, a renda $\left(y_{o}\right)$ do analfabeto poderá ser maior do que na ausência de externalidade. Para tanto, a renda do analfabeto será $y_{p}$ se ele receber a externalidade da alfabetização e $y_{1}$ se não receber. Claramente, $y_{p}>y_{1}$.

No modelo de Basu et al., os alfabetizados não irão excluir os analfabetos dos benefícios da externalidade da alfabetização, $y_{o}=y_{p}$, se e somente se $U_{L}\left(x\left(y_{p}\right)\right)$ $\geq U_{L}\left(x\left(y_{1}\right)\right)$, em que $x\left(y_{p}\right)$ e $x\left(y_{1}\right)$ são dados pela equação (2.2). Os autores identificam, ainda, casos especiais em que os alfabetizados podem optar por não excluir dos analfabetos os benefícios da alfabetização, como, por exemplo, quando as utilidades são iguais $\left(U_{L}(x)=U_{o}(x)\right)$ ou quando ambos os bens são normais e $\lambda\left(y_{O}\right)=\lambda$ para todo $\left(y_{O}\right)$.

Na visão dos autores, para que uma pessoa compartilhe a sua alfabetização com um analfabeto é necessário que ambos tenham preferências similares, ou que o poder de barganha (capturado por $\lambda$ ) não mude muito em favor do analfabeto quando os benefícios forem compartilhados. Para formalizar a proposição, os autores, consideraram um caso especial: $U_{L}(x)=x_{1} \mathrm{e}$ $U_{o}(x)=x_{1}+A x^{\alpha}{ }_{2}, \operatorname{com} \alpha<1$.

Dessa forma, como $A$ tende a $\mathrm{o}$, as duas funções de utilidade tendem a convergir. Além disso, $p_{2}=1$. Assim, o problema da família é maximizar:

4 Os autores ressaltam que $\mathrm{x}$ depende também $p$ e $y_{L}$. Porém, por hipótese, $y_{L}$ foi considerada constante e, por tanto, será ignorada. 
FRACALANZA, P. VIEIRA, K. P. As universidades federais mineiras estão se tornando mais desiguais?...

$$
\begin{gathered}
\lambda\left(y_{0}\right)\left(x_{1}+A x_{2}^{\alpha}\right)+\left[1-\lambda\left(y_{o}\right)\right] x_{1} \\
p_{1} x_{1}+x_{2} \leq y_{L}+y_{o}
\end{gathered}
$$

Isso é equivalente ao problema da maximização:

$$
x_{1}+\lambda\left(y_{O}\right) A\left(y_{L}+y_{O}-p_{1} x_{1}\right)^{a}
$$

Da Condição de Primeira Ordem se obtém:

$$
x_{1}=y_{L}+y_{o}-\left[p_{1} \lambda\left(\mathrm{y}_{0}\right) \alpha A\right]^{(1 /(1-\alpha))}
$$

Dessa forma, os autores demonstram que mudando $y_{o}$ de $y_{1}$ para $y_{p}$ aumentará $x_{1}$ enquanto $\lambda\left(y_{p}\right)-\lambda\left(y_{1}\right)$ for suficientemente pequeno ou $A$ for suficientemente pequeno. Obviamente, se qualquer um desses termos for zero, $x_{1}$ deverá aumentar. Se $A$ for pequeno, ambos os membros têm preferências similares, se $A=0$, as preferências são idênticas.

Por fim, os autores testaram a hipótese de que os analfabetos não isolados (ANI) estão em melhor situação do que os analfabetos isolados (AI). O estudo empírico de Basu et al. será apresentado na próxima seção.

\section{Revisão da Literatura}

Em relação à desigualdade social, Soares et al. (2006) avaliaram os programas de transferência de renda e suas respectivas contribuições para a redução da desigualdade de renda no Brasil no período de 1995 e 2004. No estudo realizado verificou-se que o Benefício de Prestação Continuada (BPC) 5 e o PBF, em conjunto, causaram a queda do índice de Gini em 28\%, no período de 1995 a 2004, sendo que o Bolsa-Família foi responsável por 21\% dessa redução.

Para o período de 2004 a 2006, Costa e Salvato (2008) analisaram o impacto do PBF nas variáveis pobreza, desigualdade, distribuição de renda e focalização, utilizando como metodologia os índices FGT( $\alpha$ ), Theil e Gini, o método kernel density e um indicador de focalização. O estudo concluiu que nesse período o PBF reduziu a pobreza em $20 \%$ e a desigualdade em $2 \%$.

Em relação ao indicador emprego, Leichsenring (2010) cruzou os dados da Rais $^{6}$ com os do CadÚnico, do período de 2004 a 2007, com o intuito de verificar a dinâmica de entrada e saída do mercado de trabalho formal da população beneficiária do $\mathrm{PBF}$, utilizando como metodologia o modelo de análise de sobrevivência.

5 O BPC é uma transferência de renda sem condicionalidades. O benefício corresponde a um salário mínimo mensal que é pago às pessoas idosas com 65 anos ou mais, e às pessoas portadoras de deficiência incapacitadas para a vida independente e para o trabalho, desde que tenham renda familiar per capita inferior a $1 / 4$ do salário mínimo nacional.

6 A Relação Anual de Informações Sociais (Rais) é a principal base de dados sobre emprego formal. 
O resultado desse cruzamento relatou que a inserção dos beneficiários do PBF no mercado formal é bastante precária, pois o tempo de permanência no emprego de um beneficiário (11,3 meses) é praticamente a metade do tempo de um não beneficiário (22,8 meses). No que se refere ao desemprego, foi verificado que os beneficiários possuem maior tempo de permanência nessa situação do que os não beneficiários.

Tavares (2010) investigou a existência de um possível incentivo adverso à oferta de trabalho das mães beneficiadas pelo Programa Bolsa Família. Tavares utilizou o procedimento propensity score matching para selecionar três grupos de controle. A autora averiguou que mesmo existindo um efeito-renda negativo sobre as decisões de trabalho das mães em decorrência do valor do benefício, ele não é suficiente para gerar um desincentivo à oferta de trabalho das mães beneficiárias do PBF. Segundo a autora, há um aumento das horas trabalhadas das mães devido à existência de um efeito-substituição positivo que decorre, provavelmente, da redução da oferta de trabalho dos filhos em consequência do aumento da frequência escolar destes.

Já em relação às externalidades da alfabetização, Basu et al. (2001) utilizando os dados do Household Expenditure Survey de Bangladesh 19951996, investigaram se os salários dos trabalhadores analfabetos (homens e mulheres), residentes nas zonas urbana e rural de Bangladesh, são afetados pela alfabetização de outros membros da unidade familiar.

Desse estudo, os autores concluíram que os rendimentos dos analfabetos (tanto homens quanto mulheres) são afetados positivamente pela existência de ao menos uma pessoa alfabetizada na família. Por exemplo, os homens analfabetos e casados que trabalham nos setores urbano e rural não-agrícola recebem até $15 \%$ a mais em média se eles vêm de uma família em que pelo menos uma pessoa é alfabetizada.

Nessa mesma linha de pesquisa, Gibson (2001) utilizou os dados da National Household Survey de Papua-Nova Guiné (1996) com o intuito de verificar se a alfabetização dos pais tinha alguma influência na saúde dos filhos (verificado através da estatura média das crianças de zero a cinco anos de idade). Nesse estudo, o autor concluiu que a alfabetização dos pais tem relação positiva com a saúde dos filhos. Foi possível verificar que tanto a alfabetização de adultos quanto a proporção de adultos ANI em uma comunidade influenciam o indicador de estatura das crianças de Papua Nova Guiné. Por fim, foi observado que mulheres alfabetizadas geram maiores externalidades positivas do que homens alfabetizados.

Por fim, Garcia (2009), utilizando os dados do Censo Demográfico de 2000, buscou evidências de externalidade da alfabetização dentro dos domicílios brasileiros, na direção dos filhos para os pais. $\mathrm{O}$ autor parte do pressuposto de que filhos alfabetizados podem influenciar no rendimento do trabalho de 
pais analfabetos, e na participação dos mesmos na população economicamente ativa. Para isso, realizou estimações pelo método dos Mínimos Quadrados Ordinários (MQO) e por variáveis instrumentais. Os resultados encontrados por Garcia nas estimações por MQO sugerem a existência de correlação positiva entre a alfabetização dos filhos e o desempenho dos pais. Todavia, quando o autor realizou estimações utilizando variáveis instrumentais, os resultados de MQO não foram confirmados.

\section{Estratégia empírica}

Primeiramente, foi estimada a equação de Mincer, pelo método dos Mínimos Quadrados Ordinários (MQO). A equação estimada para o chefe de família ou cônjuge (ambos analfabetos e beneficiários do PBF) é a seguinte:

$$
\ln W_{\mathrm{i}}=\beta_{o}+\beta_{i} A N I_{i}+\sum_{j=2}^{J} \beta_{j} X_{j i}+\varepsilon_{i} \quad i=(1, \ldots, n)
$$

ln $W_{i}=$ logaritmo do rendimento bruto mensal de todos os trabalhos do indivíduo $i$ (sem levar em consideração as transferências do Governo, como, por exemplo, o PBF);

$A N I_{i}=$ variável dummy para analfabeto não isolado, em que $A N I$ igual a 1 significa que o indivíduo $i$ (chefe de família ou cônjuge) possui ao menos um filho alfabetizado, e zero caso contrário;

$X_{j i}=$ representa uma das $j$ variáveis das características observadas do indivíduo $i$ (estado civil, gênero, idade, dummy para cor branca (brancos ou amarelos), Unidade da Federação, local do domicílio (urbano/rural), dummy para chefe do domicílio, jornada de trabalho ${ }^{7}$ );

$\varepsilon_{\mathrm{i}}=$ erro estocástico (fatores não observáveis) do indivíduo $i$.

Para que a aplicação dos Mínimos Quadrados Ordinários (MQO) ao problema proposto resulte na identificação causal entre externalidades da alfabetização e rendimento do trabalho dos adultos, adota-se a hipótese de que condicional às variáveis que estão sendo observadas, a participação dos analfabetos no mercado de trabalho é aleatória, ou seja, não há nada de sistemático que torne o grupo de pessoas trabalhadoras e que auferem renda diferente do grupo de pessoas que não trabalha e, portanto, não aufere.

Entretanto, para aquelas pessoas que não trabalhavam o salário observado é zero. Fato esse que torna o salário potencial das pessoas desocupadas desconhecido. Possivelmente algumas pessoas levam em consideração o custo de oportunidade da sua força de trabalho, ou seja, pode ser que existam pessoas decididas a não trabalhar pelo valor do salário vigente, e, assim, pelo indivíduo i nas seguintes atividades: trabalho principal, trabalho secundário e outros trabalhos. 
reservam o seu tempo para outras atividades. Portanto, estimar determinantes dos salários a partir de informações de uma subpopulação (no caso, a dos ocupados no mercado de trabalho) denota que a amostra é selecionada e, portanto, pode gerar estimativas viesadas sob a ótica do viés de seleção.

Nesse contexto, a correção para o problema acima referido se dá pelo modelo de seleção de Heckman, que consiste na criação de uma variável $\lambda$ chamada de Inverse Mills Ratio (IMR). Primeiramente, estima-se a "equação de seleção" por probit, para prever a probabilidade dos chefes de família ou cônjuges estarem ocupados (essa amostra conta com indivíduos ocupados e desocupados), segundo algumas variáveis explicativas, onde a variável dependente assume o valor um se o indivíduo é ocupado, e zero se o indivíduo é não-ocupado. Logo após, estima-se a “equação estrutural” (equação 4.1), acima referida, com o devido acréscimo da variável $I M R$ às demais variáveis explicativas.

Na equação de seleção, além das variáveis da equação 4.1, são incluídas mais duas variáveis: acesso e uso de telefone celular e de rádio. Estas variáveis são as chamadas variáveis de exclusão da equação de seleção, e são as responsáveis por determinar a participação dos indivíduos no mercado de trabalho. A escolha destas duas variáveis em particular para a equação de seleção é justificada pelo fato de que uma pessoa detentora de tais equipamentos eletrônicos, possivelmente, encontra-se em uma situação melhor do que aquelas que não possuem esses equipamentos, em termos de acesso a informações do mercado de trabalho. Por exemplo, a pessoa que possui um aparelho de rádio pode escutar na programação local uma possível oferta de emprego. Tal informação é comumente divulgada pelas emissoras locais de rádio e são oriundas do Sistema Nacional de Emprego (SINE) ou da Câmara de Dirigentes Lojistas (CDL). Já uma pessoa que possui um aparelho de telefone celular pode ser mais facilmente contatada para uma seleção de emprego.

Colocando a modelagem de Heckman em termos formais, parte-se da clássica equação minceriana para determinação de salários (Mincer 1974):

$$
y=x \beta+u, \quad u \sim \mathrm{N}(0,1)
$$

A primeira etapa consiste em estimar uma “equação de seleção" por probit:

$$
\Gamma=1[\mathrm{G} \delta+v]>0, \quad v \sim \mathrm{N}(0,1)
$$

As hipóteses do modelo são que G e $\Gamma$ são sempre observados e $y$ é observado quando $\Gamma=1 ; u$ e $v$ são independentes de $\mathrm{G} ; \mathrm{e} \mathrm{E}(u / v)=\gamma v$.

Dessa forma,

$$
\begin{aligned}
\mathrm{E}(y / x ; \Gamma=1)=\mathrm{E}(y / x ; \mathrm{G} ; \mathrm{v}) & =x \beta+\gamma \mathrm{E}(v / \mathrm{G} ; \Gamma=1) \\
& =x \beta+\gamma \mathrm{E}(v / v>-\mathrm{G} \delta)
\end{aligned}
$$


Sob a hipótese de que $v \sim \mathrm{N}(0,1)$, temos:

$$
\mathrm{E}(v / v>-\mathrm{G} \delta)=\lambda(\mathrm{G} \delta)
$$

Realizando, então, a devida substituição, temos:

$$
\mathrm{E}(y / x ; \Gamma=1)=\mathrm{E}(y / x ; \mathrm{G} ; v)=\mathrm{x} \beta+\gamma \lambda(\mathrm{G} \delta)
$$

Portanto, desse probit resultou a $I M R=\lambda(\mathrm{G} \delta)$. A segunda etapa consiste em acrescentar a variável $I M R$ às variáveis explicativas da "equação estrutural":

$$
\ln W_{i}=\beta_{o}+\beta_{1} A N I_{i}+\sum_{j=2}^{J} \beta_{j} X_{j i}+\gamma \lambda(G \delta)_{i}+\varepsilon_{i} \quad i=(1, \ldots, n)
$$

Isso posto, inserindo a variável IMR à equação 4.1, corrige-se o problema (viés de seleção decorrente da informação dos salários). Poder-se-á, então, estimar a equação 4.7 por MQO, a fim de verificar se as variações nos salários dos analfabetos (com renda per capita familiar de até R \$ 120,00) são influenciadas pela alfabetização dos filhos (os quais precisam cumprir a condicionalidade de frequência mínima escolar de $85 \%$ para que a família permaneça inserida no Programa).

Para verificar se os pais/adultos analfabetos são beneficiados pela alfabetização dos filhos em decorrência das condicionalidades educacionais do PBF, foram adotadas as seguintes medidas:

1. Utilizou-se para a análise informações da PNAD 2006, por ser a última fonte de dados disponível, em nível domiciliar, que trata do PBF;

2. Em busca de informações acerca da existência, ou não, da externalidade da alfabetização dentro dos domicílios beneficiários do PBF, foram realizados alguns cortes nos microdados da PNAD 2006, a fim de se obter uma população comparável. Os cortes se deram na seguinte ordem:

2.1. Foram excluídos da amostra: as pessoas com idade inferior a 8 anos; todos os domicílios que possuíam renda per capita familiar superior a $\mathrm{R} \$$ 120,o0; todos os domicílios que continham ao menos um adulto alfabetizado, e todos os domicílios que continham filhos alfabetizados com idade superior a 15 anos. Esses cortes foram necessários para captar as externalidades da alfabetização oriundas dos filhos menores de 15 anos, e para testar, no curto prazo, as contrapartidas educacionais do $\mathrm{PBF}$;

2.2. E foram selecionados aqueles domicílios que continham crianças com idade de 8 a 15 anos, acompanhadas de pai e mãe, só de pai ou só de mãe, sem pai e sem mãe, e/ou de outros adultos, todos analfabetos (com idade superior a 15 anos). 
É preciso ser dito que a hipótese crucial de identificação do impacto de interesse se sustenta no fato de que a participação no programa bolsa família estimula a educação dos filhos em decorrência das condicionalidades educacionais do programa, e, portanto, tal participação exerce influência positiva sobre a probabilidade de alfabetização das crianças.

\section{Análise dos resultados}

Nesta seção serão apresentados os resultados obtidos nas equações de trabalho dos pais/adultos analfabetos beneficiários do Programa Bolsa Família, que, em decorrência das contrapartidas educacionais, estão sujeitos às externalidades da alfabetização. Na tabela 3 encontram-se as estatísticas descritivas da amostra que foi utilizada nas regressões. Destaca-se o fato que dos 582 analfabetos presentes na amostra selecionada $65.9 \%$ são ANI.

TABELA 3. ESTATÍSTICAS DESCRITIVAS

\begin{tabular}{|c|c|c|c|c|c|}
\hline \multicolumn{6}{|c|}{ Chefes do domicílio ou cônjuges } \\
\hline Variáveis & Observ. & Média & Desv. Padrão & Mínimo & Máximo \\
\hline lnRenda & 582 & 4,904996 & 0,8602279 & 1.386294 & 6.214608 \\
\hline ANI & 582 & 0,6580756 & 0,4747625 & 0,00 & 1,00 \\
\hline Idade & 582 & 39,41581 & 10,05641 & 19,00 & 91,00 \\
\hline Cor (branco) & 582 & 0,2010309 & 0,4011159 & 0,00 & 1,00 \\
\hline Chefe do domicílio & 582 & 0,8178694 & 0,3862841 & 0,00 & 1,00 \\
\hline Casado & 582 & 0,8608247 & 0,3464271 & 0,00 & 1,00 \\
\hline Gênero1 (homem) & 582 & 0,7250859 & 0,446855 & 0,00 & 1,00 \\
\hline Zona urbana & 582 & 0,419244 & 0,4938598 & 0,00 & 1,00 \\
\hline Jornada trabalho & 582 & 40,47423 & 14,2028 & 2,00 & 88,00 \\
\hline Telefone celular & 582 & 0,1065292 & 0,3087791 & 0,00 & 1,00 \\
\hline Rádio & 582 & 0,7044674 & 0,4566743 & 0,00 & 1,00 \\
\hline
\end{tabular}

Fonte: PNAD 2006.

Foram estimadas quatro equações para captar as externalidades da alfabetização sobre o rendimento do trabalho. A tabela 4 apresenta os impactos da alfabetização dos filhos sobre os rendimentos do trabalho dos pais analfabetos e beneficiários do PBF. As equações MQO2 e HECKMAN2 possuem como controle adicional a variável "jornada de trabalho", utilizada para controlar possíveis efeitos negativos do aumento da renda do PBF sobre a oferta de trabalho dos beneficiários. 
FRACALANZA, P. VIEIRA, K. P. As universidades federais mineiras estão se tornando mais desiguais?...

TABELA 4. ESTIMAÇÕES DOS MODELOS DE MQO

\begin{tabular}{|c|c|c|}
\hline & MQO1 & $\mathrm{MQO} 2$ \\
\hline Variáveis & lnRenda & lnRenda \\
\hline ANI & $\begin{array}{r}0,1113^{*} \\
(0,0655)\end{array}$ & $\begin{array}{r}0,1092^{*} \\
(0,0645)\end{array}$ \\
\hline Idade & $\begin{array}{r}-0,0077^{* * *} \\
(0,0033) \\
\end{array}$ & $\begin{array}{r}-0,0069^{* * *} \\
(0,0033)\end{array}$ \\
\hline Branco & $\begin{array}{r}-0,1233 \\
(0,0773)\end{array}$ & $\begin{array}{r}-0,1085 \\
(0,0765)\end{array}$ \\
\hline Chefe & $\begin{array}{l}0,2582^{*} \\
(0,1485)\end{array}$ & $\begin{array}{l}0,2513^{*} \\
(0,1494)\end{array}$ \\
\hline Casado & $\begin{array}{r}0,0855 \\
(0,1684) \\
\end{array}$ & $\begin{array}{r}0,0856 \\
(0,1649) \\
\end{array}$ \\
\hline Homem & $\begin{array}{r}0,7645^{* * * *} \\
(0,1491)\end{array}$ & $\begin{array}{r}0,6261^{* * *} \\
(0,1549) \\
\end{array}$ \\
\hline Zona urbana & $\begin{array}{r}0,1739^{* * * *} \\
(0,0643) \\
\end{array}$ & $\begin{array}{r}0,1645^{* * *} \\
(0,0634) \\
\end{array}$ \\
\hline Jorn. Trabalho & - & $\begin{array}{r}0,0110^{* * * *} \\
(0,0024)\end{array}$ \\
\hline Telefone & - & - \\
\hline Rádio & - & - \\
\hline Constante & $\begin{array}{r}4,2843^{* * *} \\
(0,1955) \\
\end{array}$ & $\begin{array}{r}3,8955^{* * *} \\
(0,2188)\end{array}$ \\
\hline /athrho & - & - \\
\hline /lnsigma & - & - \\
\hline $\mathrm{R} 2$ & 0,3419 & 0,3684 \\
\hline R2 Ajustado & 0,3061 & 0,3328 \\
\hline \multirow{2}{*}{$\begin{array}{l}\text { Observ. (amostra } \\
\text { e população) }\end{array}$} & 582 & 582 \\
\hline & 4013 & 4013 \\
\hline
\end{tabular}

Fonte: PNAD 2006.

Notas: desvio padrão entre parênteses. Outros controles utilizados nas estimações são as variáveis dummies de

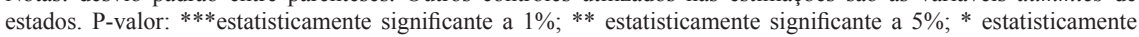
significante a $10 \%$. 
FRACALANZA, P. VIEIRA, K. P. As universidades federais mineiras estão se tornando mais desiguais?...

TABELA 4. ESTIMAÇÕES DOS MODELOS DE HECKMAN

\begin{tabular}{|c|c|c|c|c|}
\hline & \multicolumn{2}{|c|}{ HECKMAN1 } & \multicolumn{2}{|c|}{ HECKMAN2 } \\
\hline Variáveis & lnRenda & Eq. Seleção & lnRenda & Eq. Seleção \\
\hline ANI & $\begin{array}{c}0,1102^{*} \\
(0,0662)\end{array}$ & $\begin{array}{r}0,2226^{*} \\
(0,0900)\end{array}$ & $\begin{array}{c}0,1096^{*} \\
(0,0640)\end{array}$ & $\begin{array}{r}0,2228^{*} \\
(0,0900)\end{array}$ \\
\hline Idade & $\begin{array}{r}-0,0076^{* *} \\
(0,0032)\end{array}$ & $\begin{array}{c}-0,0117^{* * *} \\
(0,0043)\end{array}$ & $\begin{array}{r}-0,0070^{* *} \\
(0,0031)\end{array}$ & $\begin{array}{l}-0,0117^{* * *} \\
(0,0043)\end{array}$ \\
\hline Branco & $\begin{array}{r}-0,1233 \\
(0,0751)\end{array}$ & $\begin{array}{l}-0,0288 \\
(0,1098)\end{array}$ & $\begin{array}{r}-0,1085 \\
(0,0736) \\
\end{array}$ & $\begin{array}{r}-0,0292 \\
(0,1098) \\
\end{array}$ \\
\hline Chefe & $\begin{array}{c}0,2555^{*} \\
(0,1400)\end{array}$ & $\begin{array}{l}0,5233^{*} \\
(0,1749)\end{array}$ & $\begin{array}{l}0,2523^{*} \\
(0,1343)\end{array}$ & $\begin{array}{l}0,5239^{*} \\
(0,1747)\end{array}$ \\
\hline Casado & $\begin{array}{r}0,0865 \\
(0,1330)\end{array}$ & $\begin{array}{r}-0,1354 \\
(0,1889) \\
\end{array}$ & $\begin{array}{r}0,0852 \\
(0,1299) \\
\end{array}$ & $\begin{array}{r}-0,1349 \\
(0,1886) \\
\end{array}$ \\
\hline Homem & $\begin{array}{r}0,7571^{* * * *} \\
(0,1942)\end{array}$ & $\begin{array}{r}1,4475^{* * *} \\
(0,1714)\end{array}$ & $\begin{array}{r}0,6288^{* * * *} \\
(0,1771) \\
\end{array}$ & $\begin{array}{r}1,4470^{* * *} \\
(0,1713)\end{array}$ \\
\hline Zona urbana & $\begin{array}{r}0,1740^{* * * *} \\
(0,0641)\end{array}$ & $\begin{array}{r}-0,0520 * * * \\
(0,0929)\end{array}$ & $\begin{array}{r}0,1645^{* * *} \\
(0,0628)\end{array}$ & $\begin{array}{r}0,0521^{* * *} \\
(0,929)\end{array}$ \\
\hline Jorn. Trabalho & - & - & $\begin{array}{l}0,0115^{* * *} \\
(0,0030)\end{array}$ & - \\
\hline Telefone & - & $\begin{array}{r}0,3244^{* *} \\
(0,1533)\end{array}$ & - & $\begin{array}{l}0,3227^{* * *} \\
(0,1528)\end{array}$ \\
\hline Rádio & - & $\begin{array}{r}0,1081 \\
(0,1008)\end{array}$ & - & $\begin{array}{r}0,1104 \\
(0,1002) \\
\end{array}$ \\
\hline Constante & $\begin{array}{r}4,2865^{* * * *} \\
(0,7196)\end{array}$ & $\begin{array}{r}-7,2675^{* * * *} \\
(28.745,4629) \\
\end{array}$ & $\begin{array}{r}3,8947^{* * * *} \\
(0,7090)\end{array}$ & $\begin{array}{r}-7,1114^{* * * *} \\
(17.538,6795)\end{array}$ \\
\hline /athrho & $\begin{array}{r}-0,0125 \\
(0,2541) \\
\end{array}$ & - & $\begin{array}{r}0,0046 \\
(0,2186) \\
\end{array}$ & - \\
\hline /lnsigma & $\begin{array}{r}-0,3606^{* * * *} \\
(0,0293)\end{array}$ & - & $\begin{array}{r}-0,3811^{* * *} \\
(0,0293)\end{array}$ & - \\
\hline Observ. & \multicolumn{2}{|c|}{582} & \multicolumn{2}{|c|}{582} \\
\hline população) & \multicolumn{2}{|c|}{4013} & \multicolumn{2}{|c|}{4013} \\
\hline
\end{tabular}

Fonte: PNAD 2006.

Notas: desvio padrão entre parênteses. Outros controles utilizados nas estimações são as variáveis dummies de estados. P-valor: $* * *$ estatisticamente significante a $1 \% ; * *$ estatisticamente significante a $5 \%$; estatisticamente significante a $10 \%$. 
Nos quatro modelos de rendimento do trabalho, os coeficientes das características pessoais dos beneficiários do PBF têm o sinal esperado de acordo com outros trabalhos: ser chefe de domicílio ou homem elevam em média os rendimentos do trabalho, respectivamente, em $25,23 \%$ e $62,88 \%$ (HECKMAN2); residir em zona urbana, eleva em média o rendimento em $16,45 \%$. A cor branca (brancos ou amarelos) para os analfabetos pertencentes a famílias com renda per capita familiar de até $\mathrm{R} \$ 120,00$ não é significativa.

As equações de seleção dos modelos Heckman sugerem que das duas variáveis de exclusão da equação de seleção, apenas a variável ter telefone celular é significativa para que os analfabetos, beneficiários do Programa Bolsa Família, sejam selecionados ao mercado de trabalho. Em HECKMAN2, aqueles analfabetos que possuem aparelho de telefone celular têm probabilidade $32,27 \%$ maior de serem selecionados do que os que não têm.

Nas quatro equações, os impactos positivos da variável ANI demonstram que possuir ao menos um filho alfabetizado é, na média, sinal de aumento nos rendimentos do trabalho. Nas estimativas da equação MQO1, os pais/adultos ANI, beneficiários do PBF, têm os rendimentos do trabalho, em média, 11,13\% maiores que os pais que não possuem filhos alfabetizados (AI). Quando essa mesma população foi analisada pelo modelo de seleção de Heckman (equação HECKMAN1) a magnitude do impacto ficou praticamente inalterada, pois o coeficiente estimado de ANI passou a impactar, em média, 11,02\% a mais para os pais/adultos ANI, com um nível de significância de 10,00\%. Na equação HECKMAN2, a qual conta, também, com o controle da variável "jornada de trabalho", os resultados sugerem que os pais/adultos ANI obtêm rendimentos 10,96\% maiores do que os pais/adultos também beneficiários do PBF, que não possuem filho alfabetizado (AI).

\section{Considerações Finais}

Este trabalho se propôs a investigar um possível benefício positivo da alfabetização para os adultos analfabetos, que tenham filhos alfabetizados em idade escolar, inseridos no PBF, em decorrência das condicionalidades educacionais do Programa já no curto prazo. Buscaram-se sinais de externalidade da alfabetização no sentido dos filhos, em atividade escolar, para os pais/adultos analfabetos, no quesito rendimentos do trabalho.

Devido ao viés de seleção decorrente da informação dos salários, os resultados preliminares obtidos via estimações por Mínimos Quadrados Ordinários (MQO) provavelmente apresentam-se viesados. Para corrigir tal problema, foi utilizado o modelo de seleção de Heckman que corrige o viés de seleção e gera um contrafactual mais adequado para a investigação do impacto de interesse. 
Os resultados mostram que, ceteris paribus, há correlação positiva, no âmbito intra-domiciliar, entre a alfabetização dos filhos e os rendimentos do trabalho dos pais analfabetos. Dessa forma, os pais/adultos analfabetos (ANI), beneficiários do Programa Bolsa Família, que possuem ao menos um filho alfabetizado recebem, em média, 10,96\% a mais do que os pais/adultos analfabetos (AI), beneficiários do PBF, que não possuem filhos alfabetizados ou em atividade escolar. Essa magnitude do impacto está muito próxima ao que já foi observado na literatura que investiga externalidades da alfabetização.

Portanto, em decorrência das contrapartidas educacionais do PBF, o nível de bem-estar da família pode ser ampliado já no curto prazo, uma vez que o aumento da renda disponível proporciona a expansão da curva de restrição orçamentária do conjunto familiar. Além disso, o resultado obtido corrobora outros que atribuem ao PBF a redução da pobreza no país.

\section{Referencias}

BASU, K.; FOSTER, J. (1998). “On Measuring Literacy”. Economic Journal, vol. 108; p. 173-349.

BASU, K.; NARAYAN, A.; RAVALLION, M. (2001). "Is Literacy Shared Within Households? Theory and Evidence from Bangladesh". Journal of Labor Economics, vol. 8; p. 649-655.

BOROOAH, V. K. (2002). "The Role of Maternal Literacy in Reducing the Risk of Child Malnutrition in India”. International Centre for Economic Research, ICER Working Papers, n. ${ }^{\circ}$ 31-2002.

CACCIAMALI, M. C.; TATEI, F.; BATISTA, N. F. (2008). "Impactos do Programa Bolsa Família Federal sobre o trabalho infantil e a frequência escolar". Revista Economia Contemporânea, vol. 14(2).; p. 269-301.

CARVALHO, A. P.; NERI, M. C.; SILVA, D. B. (2006). “Diferenciais de Salários por Raça e Gênero: Aplicação dos procedimentos de Oaxaca e Heckman em Pesquisas Amostrais Complexas”. XV Encontro Nacionais de Estudos Populacionais, 15. Caxambu.

COSTA, A. A. B.; SAlVATO, M. A. (2008). Análise do Programa de Transferência de Renda Bolsa Família para o período 2004-2006: impactos sobre pobreza, desigualdade e focalização. URL [on-line]: <http://www.ipcundp.org/publications/mds/41P.pdf> Acesso em: 14 set. 2011.

LEICHSENRING, A. R. (2010). "Precariedade laboral e o programa bolsa família." In: CASTRO, J.A. MODESTO, L. [org.]. Bolsa Família 2003-2010: avanços e desafios. Brasília: Instituto de Pesquisas Econômicas Aplicadas (Ipea).

MINISTÉRIO DO DESENVOLVIMENTO SOCIAL E COMBATE À FOME. Programa Bolsa Família. URL [on-line]: <http://www.mds.gov.br/bolsafamilia > Acesso em 02 jul. 2011. 
GARCIA, F. R. (2009). Novas medidas de alfabetização e suas implicações: evidências para o Brasil. Dissertação de Mestrado. Escola de Economia de São Paulo da Fundação Getulio Vargas (EESP/FGV).

GIBSON, J. (2001). “Literacy and Intrahousehold Externalities”. World Development, vol. 29; p. 155-166.

GLEWWE, P.; KASSOUF, A. L. (2008). "O Impacto do Programa Bolsa Família no total de matrículas do ensino fundamental, taxas de abandono e aprovação”. Anais do Encontro Nacional de Economia, 36. Salvador.

SANTOS, C. M. (2011). Participação no mercado de trabalho entre elegíveis ao Programa Bolsa Família no Estado de Minas Gerais. URL [on-line]: <http:// www.poseconomia.ufv.br/docs/Artigo\%2oProfa\%20Cristiane\%20M\%20 Santos.pdf>. Acesso em: 01 jul. 2011.

SEN, A. (2000). Desenvolvimento como liberdade. São Paulo: Companhia das Letras.

SOARES, F. V.; RIBAS, R. P.; OSÓRIO, R. G. (2007). Evaluating the Impact of Brazil's Bolsa Família: Cash Transfer Programmes in Comparative Perspective. URL [on-line]: <http://www.ipc-undp.org/pub/IPCEvaluationNote1.pdf> Acesso em: 01 jul. 2011.

SOARES, S.; SÁTYRO, N. (2010). “O programa bolsa família: desenho institucional e Possibilidades futuras”. CASTRO, J. A.; MODESTO, L. [org.]. Bolsa Família 2003-201O: avanços e desafios. Brasília: Ipea.

TAVARES, P.A. (2010). "Efeito do Programa Bolsa Família sobre a oferta de trabalho das mães”. Economia e Sociedade, vol. 19( 3); p. 613-635.

TEIXEIRA, C. G. (2008). Análise do impacto do Programa Bolsa Família na oferta de trabalho dos homens e mulheres. URL [on-line]: <http://www.ipcundp.org/ publications/mds/27P.pdf> Acesso em: 14 ago. 2011.

SOUZA, A. P. (2011). "Políticas de Distribuições de Renda no Brasil e o Bolsa-Família. C-Micro”. Working Paper, n. ${ }^{\circ}$ o1/2011. URL [on-line]: <http:// bibliotecadigital.fgv.br/dspace/bitstream/handle/10438/8251/TD\%20281\%20-\%20C-Micro\%2001\%20\%20Andr\%C3\%A9\%2oPortela.pdf?sequence=1> Acesso em: 08 set. 2011.

VALENTI. P. M. (2002). "Should We Be Concerned About The Distribution of The Literacy Across Households? An Axiomatic Investigation”. CAE Working Paper \#02-15, 2002. URL [on-line]: <www.arts.cornell.edu/econ/cae/Valenti_ Literacy.pdf $>$ Acesso em: 13 out. 2011.

Recebido em: 16 de dezembro de 2011

Aceito em: 06 de novembro de 2012 
